\title{
Selected Reference Books of 1991-92
} \section{Eileen McIlvaine}

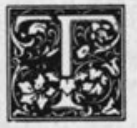

his article follows the pattern set by the semiannual series initiated by the late Constance $M$. Winchell more than thirty years ago and continued by Eugene Sheehy. Because the purpose of the list is to present a selection of recent scholarly and general works of interest to reference workers in university libraries, it does not pretend to be either well balanced or comprehensive. A brief roundup of new editions of standard works, new titles in series already considered reference, and pieces received on continuations orders is provided at the end of the article. Code numbers (such as $\mathrm{AD} 540$ and CJ331) have been used to refer to titles in the Guide to Reference Books, 10th ed., (Chicago: American Library Assn., 1986) or to the Supplement . . Covering Materials from 1985-1990 (Chicago: 1992).

\section{NATIONAL BIBLIOGRAPHIES}

CLIO: catalogo dei libri italiani dell'Ottocento (1801-1900)/Catalogue of Nineteenth Century Italian Books. Milano: Ed. Bibliografica, [1991]. 19v. L6,500,000.

CLIO is a catalog of nineteenth-century books published in Italy and Ticino, the Italian-speaking canton of Switzerland. There were some earlier general catalogs of Italian books such as Attilio Pagliaini's Catalogo generale della libreria italiana dall'anno 1847 a tutto il 1899 (Guide AA905) and a publication of the Austrian censorship office: Elenco delle opere stampate e pubblicate in Milano e nelle provincie lombarde (1815-1847), on which this publication is partially based. CLIO contains more than double the number of titles in those earlier compilations.

The bibliography includes not only books proper but also pamphlets and fascicles longer than twelve pages. Excluded are texts not in Greek or Roman alphabets, periodical publications from academies, corporations, societies and institutes, offprints, laws, decrees and ordinances, administrative publications of local governments and associations, legal papers, sales catalogs, cartography, and music without text. In total, it lists 420,898 publications, giving the location of titles in Italian public and university libraries. Only one library location is listed for each title, so this catalog has a limited usefulness as a union catalog. If the title is in the Biblioteca Nazionale in Florence, this library is given as the location; if not, a library in the region where the book was published or printed is given. There are some titles in the list without any location: works found only in bibliographies.

The bibliography is divided into three parts: (1) author/title catalog, listing works alphabetically by author, or by title for anonymous and corporate authors and works by more than three authors; (2) a list by publisher or printer, showing works chronologically arranged by year and then by author; (3) place of publication arranged alphabetically by region and town, then by year and, within the year, by author. The index is by secondary author (editors, translators, authors of prefaces, illustrators and composers) with cross-reference to the principal author and a brief

Eileen Mcllvaine is Head of Collections and Reference in the Humanities and History Division, Columbia University Libraries, New York 10027. Although it appears under a byline, this list is a project of the reference departments of Columbia University Libraries, and notes are signed with the initials of one of the following staff members: Kathe D. Chipman, Avery Library; Mary Cargill, Beth Juhl, Robert H. Scott, Sarah Spurgin, Junko Stuveras, Butler Library; Olha della Cava, School of Library Service Library; Elizabeth A. Davis, Music Library; Leigh Hallingby, Psychology Library. 
title. The index ends with a geographical list of publishers and printers.- J.S.

\section{ABBREVIATIONS}

Zalucky, Henry K. Compressed Russian: Russian-English Dictionary of Acronyms, Semiacronyms and Other Abbreviations Used in Contemporary Standard Russian with Their Pronunciation and Explicit Correlates in Russian, and Equivalents in English. Amsterdam, New York: Elsevier, 1991. 890p. (ISBN 0444987282). LC 90-42785.

The march of bureaucracy and technology through the twentieth century has left in its wake a burgeoning population of acronyms and abbreviations. In this field of human endeavor, probably no other modern society has been as productive as the former Soviet Union. (It will be interesting to see how fully the tradition is continued in the various successor states of that empire.) A dictionary to assist in decoding these elliptical structures has thus always been an essential reference tool for any student of Russian or Soviet affairs. The latest such guide for the perplexed is offered by this work compiled by Henry $\mathrm{K}$. Zalucky in the United States, printed in Poland, and published in Amsterdam. With slightly fewer than forty thousand entries, it provides a key to a host of shortened forms of the Russian names of domestic and foreign government bodies, political parties, economic enterprises, educational and research institutions, archives, journals, units of measurement, countries, languages, concepts, substances, machines, etc. The material has been compiled largely from Soviet printed sources, with a particular debt to the third edition of D. I. Alekseev's Slovar' sokrashchenii russkogo iazyka (Guide AD672). The author has aimed primarily to include those forms in current usage, but many terms of historic significance, particularly the names of earlier political organizations and state institutions, are provided as well, along with some indication of the period of their existence.

While the dictionary is designed above all for use by students and specialists, pains have been taken to accommo- date the needs of a more general Russian-language readership as well. Individual entries include a guide to pronunciation where needed (e.g., to indicate whether an acronym is pronounced as if it were a single word or whether it is spelled out), a full Russianlanguage version of the abbreviated term, a translation into English, and, where appropriate, notes indicating such things as the field in which a term is used, geographical location, or historical period. Where the same acronym is used for several different terms, each instance is treated as a separate entry, and the terms are arranged in alphabetical order of their full Russian-language equivalent. The brief supplementary list of abbreviations, several tables of symbols and units of measures such as a table of Roman numerals, a Roman-alphabet listing of chemical elements, and a list of the caloric and nutritional content of various foods are clearly aimed at the general Russian-language reader.

Inevitably, comparisons are likely to be made with another work issued by the same publisher just six years agoDictionary of Russian Abbreviations, compiled by Edgar Scheitz in the German Democratic Republic (Suppl. AD154). Curiously, this work does not figure in Zalucky's list of lexicographical sources. While both works report that they contain about 40,000 abbreviations, the earlier work in fact covers much more material, since it groups all the terms designated by a single acronym under the same entry. It does not, however, provide English translations. Naturally, too, as a work produced in a country that was at that time still firmly ensconced in the Warsaw Pact, it does not, in contrast to the Zalucky work, include such popular terms beyond the bounds of official Soviet sensibility as zek [labor camp inmate], tamizdat [émigré literature], or porno [pornography]. In addition, of course, it is slightly more out-of-date than Zalucky's volume.

Probably any library with a serious Russian reference coverage will want to add this new dictionary to its collection, although neither this book, nor probably 
any printed reference, can possibly pretend to genuine currency in today's fastchanging Russia. An increasing number of the names and even many of the institutions listed in this 1991 publication are now history, and one would search it in vain to decipher the acronyms for the country itself (RF for the Russian Federation or SNG for the Commonwealth of Independent States), let alone the host of new names and agencies springing up to replace those of an earlier age.-R.H.S.

\section{LIBRARIANSHIP}

Directory of Ethnic Professionals in LIS (Library and Information Science). Comp. George C. Grant. Winter Park, Fla.: FOUR-G Publ., 1991. 254p., 60p. \$52.95 (ISBN 0-962542324). LC 90-85845.

The Directory of Ethnic Professionals in LIS includes biographical sketches of sixteen hundred deceased, retired, or currently employed African-American library and information science professionals. The Directory was born out of the compiler's frustration with the inability to locate information about black librarians in national, regional, and professional biographical sources. He has, however, extended his coverage to "all ethnic librarians," and whereas the inclusion of a number of professionals of Chinese American, Japanese American, Hispanic, Mexican American, and $\mathrm{Na}$ tive American heritage is understandable, the extension of the work to include some foreign librarians working in their native countries, such as Ghana, Senegal, or the Philippines, seems out of scope for an American ethnic librarians' directory.

The Directory is arranged alphabetically by last name, and one index lists entrants by employer/alma mater. In content the entries parallel closely those in ALA's two-volume Directory of Library and Information Professionals/DLIP (Suppl. AB39) including, not only the name, ethnic heritage, and current employer of each person listed but also information about his/her career, educational background, publications, and subject/consulting expertise. Although the DLIP is a much more comprehensive work, containing some forty-three thousand entries, only about 25 percent of the entries in the Directory of Ethnic Professional duplicate those in the DLIP. This mass of new biographical data for a category of professionals underrepresented in standard biographical dictionaries of the library pro-fession is reason enough for purchasing this reference tool, which the compiler hopes to expand in subsequent editions.-O.dC.

\section{RELIGION}

The Coptic Encyclopedia. Aziz S. Atiya, ed. in chief. New York: Macmillan, [1991]. 8v. (2372, 371p.) $\$ 900$ (ISBN $002897025 X)$. LC 90-23448.

Most of us know little about the Copts or their contributions to the history of Egypt and to the development of Christianity. As Lola Atiya writes in the foreword to the Encyclopedia, "It [the Coptic period] falls between the glamour of Pharaonic Egypt and the stupendous surge of Islam that swept the world." However, Coptic civilization remains a key component of both the language and landscape of modern Egypt and the spiritual and ritual foundations of the Christian church. This eight-volume set treats the people and culture, centered in Egypt, Nubia/Sudan, and Ethiopia. Coptic civilization began with the preaching of the evangelist Mark to the citizens of Alexandria in the first century A.D., reached the height of its influence in the third century, and declined-but enduredthrough over sixteen hundred years of Byzantine and Arab dominance. This project, originally conceived in the 1950 s by Professor Aziz Atiya, author of wideranging studies of Eastern Christianity and Coptic civilization, and his colleagues in the Higher Institute of Coptic Studies, was begun in earnest in 1979 and completed after twelve years and the contributions of over two hundred scholars.

The twenty-three hundred signed entries in these volumes range in length from a few sentences ("Archangel") to a dozen or more pages ("Saints"); all include bibliographies, some of which are quite extensive. Most articles are by well-known authorities in the field, such 
as P. M. Fraser writing on Alexandria, Bruce Metzger on papyri, and Elaine Pagels on texts from the Nag Hammadi Library. Many entries include black-andwhite illustrations or photographs, maps, diagrams, or tables: the article on the Coptic religious calendar, for example, presents a seventeen page list of saints' days and feasts. In addition to entries covering historical and cultural persons and topics, there are also biographical sketches of coptologists, archeologists, and theologians, as well as portraits of prominent Copts in modern Egypt. Particularly useful to the generalist are the concise and comprehensive discussions of specific monasteries, archeological sites, or other topics which are otherwise available only in (sometimes obscure) non-English publications, e.g., "Karnak in the Christian Period." The wide variety of subjects addressed testifies to the widespread influence of Coptic civilization. Alongside articles treating the Roman bureaucracy in Egypt or the development of Christian wedding customs, one finds discussions of the development of the codex book and bookbinding techniques and, following a cross-reference from the Book of Kells, a study of Coptic elements in Irish art and monasticism.

Cross-references to related subjects are indicated within the text. One needs the excellent index to locate some articles filed under confusing or unlikely headings (e.g., Saint Catherine's Monastery is under "Mount Sinai ..."). An annoying feature of the index is its use of page rather than volume numbers in references, though volumes and corresponding page numbers are provided at the bottom of each index page. Besides the index, Volume 8 also includes twelve maps and a lengthy appendix on the Coptic language, with entries on topics such as alphabets, etymology, dialects, and paleography. Volume 1 provides a general bibliography.

At \$900, The Coptic Encyclopedia is not an automatic purchase for any library, but its unique focus and depth will fill a real lacuna in reference publishing and will satisfy students and scholars in fields ranging from archeology to theology.-B.J.
Encyclopedia of the Early Church. Comp. Institutum Patristicum Augustinianum and ed. Angelo di Berardino; tr. from the Italian by Adrian Walford; with a foreword and bibliographic amendments by W. H. C. Frend. New York: Oxford Univ. Pr., 1992. 2 v. $\$ 175$ (ISBN 0-19-520-892-7). LC 91-23934.

This two-volume encyclopedic guide to the first seven or eight centuries of Christianity is a translation of an Italian work, Dizionario patristico e di antichitd cristiane, originally published between 1983 and 1988 (Guide BB310). Representing the collective efforts of a team of 167 scholars from seventeen different countries (although nearly half of them represent scholarly institutions in Rome), it covers an impressive range of topics relating to the history, geography, theology, philosophy, literature, languages, terminology, liturgy, art, architecture, archeology, and material culture of the early church from its origins until the middle of the eighth century. Considerable attention is also devoted to heresies, Gnosticism, Judaism, and the culture and philosophy of classical antiquity. An impressive effort has been made to provide coverage of the whole of the Christian world, from Mauritania to Persia, from Ireland to Aksum. Finally, a special emphasis on the biography makes this a rich source of information even on many lesser-known figures.

The individual entries, ranging from one or two paragraphs to five or six pages in length, are often accompanied by substantial bibliographies of sources and major secondary works, updated by Frend for this English-language edition. Adrian Walford's translation from the Italian reads clearly and smoothly, and a well-designed layout, numerous crossreferences, and an extensive index facilitate use of this work. Included at the end of the text are a chronological table, forty-four maps, and over three hundred illustrations, some in color.

The Encyclopedia is an outstanding contribution to the English-language literature in a field that certainly has not lacked for coverage in the past. It belongs in any serious research or col- 
lege-level collection attempting to provide coverage in the areas of Chris- tianity, late antiquity, or Western civilization in general.

Its appearance comes close on the heels of the very similarly named Encyclopedia of Early Christianity (New York: Garland, 1990), reviewed in an earlier issue of this column, but the differences between these two works are considerable. While the Garland volume is designed primarily for the nonspecialist, this work, given the depth and quality of its treatment, promises to be a regular source of reference for the specialist (although it will serve as a valuable introduction for the general reader as well). The breadth of coverage is also much greater in the volume under review here: it contains more than twice as many articles, covers a longer time period, and addresses a broader range of issues. In those cases where both provide an article on the same subject, the Oxford volume is usually (though not always) more detailed in its coverage. To be sure, there are some areas where the Garland volume provides fuller coverage or at least more ready access: two notable examples are its entries on individual canonical and uncanonical scriptural works and its occasional articles on modern scholars who have contributed significantly to the study of the early church. Finally, the Encyclopedia of Early Christianity includes valuable additional bibliographic references on many topics. Ideally, it would be good to have both, but if one could have only one, the Encyclopedia of the Early Church is clearly the superior choice.-R.H.S.

Haddad, Yvonne Yazbeck, John Obert Voll, and John L. Esposito. The Contemporary Islamic Revival: A Critical Survey and Bibliography. Bibliographies and Indexes in Religious Studies, 20. Westport, Conn.: Greenwood, 1991. 230p. (ISBN 0313247196). LC 91-12618.

The bibliography, which contains three essays and a bibliography on the Islamic resurgence, includes 1,225 books and articles and is classed by geographic area, except for the chapter "General Studies," which is divided into three parts: Interpretive Studies, Economics, and Women. Entries for books and some articles are annotated. The cited articles are drawn from over one hundred journals in Islamic and area studies. The indexes are by author, title, and subject. The subject index includes personal and place names, organizations, and broad topics.

The subject index is unfortunately not very helpful. Since the organization of the bibliography is by country and continent, a good, nongeographic topical index would have been useful. Some index terms such as development are too vague to be useful. Egypt has sixty-six items, and some of the same items are repeated on the same page under "Egyptian history," "Egyptian nationalism," etc. A reorganization of the subject index would much enhance the usefulness of the bibliography.-J.S.

Jewish-American History and Culture: An Encyclopedia. Ed. Jack Fischel and Sanford Pinsker. Garland Reference Library of the Social Sciences, 429. New York: Garland, 1992. 710p. (ISBN 082406622-7). LC 91-14188.

In recent years, librarians have been nearly overwhelmed by an alarming array of specialized subject bibliographies; the past few seasons have seen the publication of bibliographies on the history, religion, literature, theater, and film of Jews in the United States. Unfortunately, there was no comprehensive source for locating brief information on different aspects of Jewish-American life. Happily, Jewish-American History and Culture remedies this situation quite nicely, aiming to combine a "celebration" of the extraordinary richness of Jewish-American culture with "the sober judgments of scholarship, analysis, and critical detachment" (preface). The result is such a fascinating, compendious resource that reference departments will have difficulty in deciding where to place this volume; it could find a place in American history, religion, biography, popular culture, or several other sections.

This encyclopedia presents signed topical essays and biographical sketches, most 
with bibliographies, arranged in alphabetical order, and followed by a general index. An introductory table lists all articles under a series of main themes or subjects so that readers may find other entries on similar topics. These main themes, which give an idea of the scope of coverage, include arts, biographies, economics, history, humanities, Jewish organizations, libraries, literary biographies and studies, media and communications, military, Nobel Prize, political theory, pop culture, religion and religious theories, science, and social sciences. The editors have deliberately excluded some topics, such as foods or stereotypes, feeling that such materials had been adequately covered elsewhere, and that "there was little profit, and a possible danger, in confusing the trivial with the decidedly more important" (introduction).

Much of the information presented here would be difficult to locate without a lot of effort and a very large reference collection. Articles cover topics as diverse as agriculture and American attitudes toward Ethiopian Jews and include lists of all Jewish-American Nobel Prize winners as well as addresses and descriptions of American libraries with extensive Judaica collections. Recommended for all research collections.-B.J.

\section{MYTHOLOGY}

Bell, Robert E. Women of Classical Mythology: A Biographical Dictionary. Santa Barbara, Calif:: ABC-CLIO, [1991].462p. \$49 (ISBN 0-874365813). LC 91-26649.

Students already have Robert Bell to thank for two other works on classical mythology, Place Names in Classical Mythology (Suppl. CF10) and Dictionary of Classical Mythology (Guide CF23). His latest work provides twenty-six hundred biographical sketches of goddesses, nymphs, and mortals, many of whom are too obscure or peripheral to appear in other dictio-naries of mythology. Entries range in length from a sentence to several hundred words; most include references to classical sources. Longer essays for principal deities (e.g., Artemis) provide lists of birthplace(s), lovers/consorts, children, principal places of worship, sacred attributes, companions, and epithets. Cult titles or epithets make up a significant proportion of the shorter entries (e.g., "Glaucopis" for Athena). Though some readers may be put off by the occasionally flashy prose style (for example, references to mythological character's "sex lives" or a description of Hera as "coaddictive"), entries present fairly full information. One small quibble is Bell's failure to indicate which ancient authors provide us with which variants of myths and whose story he prefers.

Major cross-references are indicated in the text by capital letters, but the careful reader will find many additional related articles by checking other names mentioned in the course of an entry. An appendix, "The Men in Their Lives," lists male characters which figure in the main text; thus, by checking "Romulus" in the appendix, one can eventually find the name of the she-wolf who nursed the Roman twins. However, without a general index, Women of Classical Mythology will, to a certain extent, only serve those who already know the name of the mythological figure for whom they need information. To locate a list of all the characters associated with the Acropolis or all those goddesses who protect women in childbirth, one needs to consult Bell's other works.-B.J.

Recent Studies in Myths and Literature, 1970-1990: An Annotated Bibliography. Comp. Bernard Accardi (and others). Bibliographies and Indexes in World Literature, 29. Westport, Conn.: Greenwood, 1991. 251p. \$45 (ISBN 0313-27545-9). LC 91-18070.

This bibliography in part attempts to inquire into post-modernist influences on the study of literature in relation to myths. Primarily compiled for scholars of Anglo-American literature, the bibliography is divided into sections such as theory and themes, classical literature, British and American literature by time period. Within the time period, the arrangement is by subject and author. All entries are accompanied by notes from one line to nearly half a page in length. Some English translations of foreign 
works are included; however, dissertations and book review are not. The index is by author (of books and articles) and subject, such as literary authors, mythological figures, themes, and scholars of mythology.-J.S.

van Keuren, Frances Dodds. Guide to Research in Classical Art and Mythology. Chicago: American Library Assn., 1991.307p. \$35 (ISBN 0838905641). LC 91-11122.

Beginning students, as well as scholars and librarians who have never had the time or inclination to develop a firm grip on the complex and confusing array of bibliographies, dictionaries, catalogs, and site reports from the fields of classical archeology, art, mythology, and iconography, should be grateful to Professor van Keuren for this new guide. Her book takes the form of a narrative bibliography in seventeen chapters, each of which discusses one or two major works in a specific field, covering the nature of research in that discipline and the organization and uses of the work in question. Following these major works are essays on and bibliographies of complementary reference works, handbooks, and additional sources. These chapters are grouped into three main sections: "General Research," which includes chapters on Greek, Etruscan, and Roman art and archeology; "Mythology," which includes chapters on myth and ancient art, literature and iconography, as well as portrayals of myth in later art and literature; and "Media Studies," which treats individual art forms, from sculpture and vase painting to interior decorating and numismatics. Author-title and subject indexes complete the volume.

Particularly helpful are Professor van Keuren's remarks on the currency and utility of certain works and on the controversy surrounding specific topics as well as her suggestions on how one might proceed in a research project after consulting one of these reference tools. English titles are provided for many foreign works, helping readers to identify in advance which German sources may be pertinent to their interests. Though librarians are not the primary audience for this work, many will benefit from the lengthy descriptions of the scope and organization of important sources, such as Beazley's catalogs of Athenian vases or the Corpus Vasorum Antiquorum. Overall, the Guide to Research in Classical Art and Mythology is a good introduction for the novice and a perfect refresher course for the more advanced scholar.-B.J.

\section{LITERATURE}

Benét's Reader's Encyclopedia of American Literature. Ed. George Perkins, Barbara Perkins, and Phillip Leininger. New York: HarperCollins, [1991]. 1,176p. \$45 (ISBN 0-062-70027-8). LC 91-55001.

Although the name echoes the new title of Benét's Reader's Encyclopedia (Suppl. BD24), this is in fact a revision of Max Herzberg's Reader's Encyclopedia of American Literature (Guide BD408); the new title reflects a change in publisher, not the posthumous involvement of William Rose Benét.

Like its predecessor, this compilation claims to be "the most comprehensive one-volume reference book in its field" (preface), and it has many more entries than the Oxford Companion to American Literature (Guide BD407), though the latter work does have information not provided in Benét's.

The new edition has retained many of the original entries, revised or eliminated others, and added some twentyfive hundred new headings "in response to contemporary critical perspectives." Many of the evaluative comments in the earlier edition have been dropped, leaving its flavor somewhat bland: the reference to "Owen Wisteria" is gone, as is Hemingway's description of Huckleberry Finn. The new edition has added entries on major Canadian and Latin American writers, many taken from Benét's Reader's Encyclopedia. It has longer, signed essays of general topics, which provide a useful overview of major trends in American literature, but some of the essays lack subtlety. One essay opines that "before the 1970's everyone knew what the classics of American literature were supposed to be" (p.327). The entry on Longfellow, 
however, has a good description of the fluctuation of his reputation.

The new edition is very useful for its entries on current American literature, but libraries will want to keep the first edition.-M.C.

\section{Fenwick, M. J. Writers of the Caribbean and}

Central America: A Bibliography. New

York: Garland, 1992. 2v. \$200 (ISBN

0-8240-4010-4). LC 91-35701.

Although this bibliography of primary works includes significantly more writers than are included in other recent bibliographies of Caribbean and Central American authors, the citations are often so incomplete that tracing the cited work would be difficult if not impossible. Writers are arranged alphabetically by country of origin, and each entry lists birth and death dates (if known), literary form, and books (giving only dates, not place or publisher), followed by work published in serials or anthologies. This last section is the most frustrating because the citations do not include the titles of the short stories, plays, or poems, and give only the title of the journal and the year that the journal was published. No issue date or page number is provided. (Often only the title of a journal is listed with no other information.) Works published in anthologies fare slightly better. Although the title of the work is not included, the editor, title, and date of the anthology are usually provided. The volumes are indexed by writer only.

Despite its considerable limitationsit can't be used to find a poem, short story, or play, no works are included after about 1988, and some citations provide only the title of a newspaper-this bibliography could still be useful to libraries with significant collections in Caribbean literature.-S.S.

Hawthorn, Jeremy. A Glossary of Contemporary Literary Theory. London: E. Arnold, (dist. in United States by Routledge, Chapman and Hall, New York), 1992. 282p. \$49.95 (ISBN 0340539127). LC 91-32095.

This glossary of literary terms offers substantial explanations of terms fre- quently used by recent literary critics and theoreticians, roughly covering the time period since 1970 . As such, it is a valuable supplement to other dictionaries of literary terms, for example, M. H. Abrams, Glossary of Literary Terms (Guide BD31) and Hugh Holman, Handbook to Literature (Guide BD39).

The entries in the glossary are longer than the usual entries in other dictionaries of literary terms and read more like short essays on literary criticism. Quotations from original sources help to elucidate the meaning of a term. Related terms are grouped together and extensively cross-referenced. The additional matter includes a list of key terms by critical school (p.xii-xv) and a bibliography of reference sources (p.xv-xvii), and a list of quoted works (p.269-82).-J.S.

\section{MUSIC}

Gooch, Bryan N. S. and David Thatcher. A Shakespeare Music Catalogue. Oxford: Clarendon, 1991. 5v. (2,847p.). \$635 (ISBN 0-19-812359-0). LC 89-9270. Contents: v.1-3, The catalogue of music; v.4, Indices; v.5, Bibliography.

This catalog is a thorough compilation containing 21,362 compositions of published and unpublished original music related to Shakespeare's literary work, composed from his day through 1987.

Volumes 1 through 3 contain the cata$\log$, beginning with the plays presented alphabetically by title. Volume 3 includes the sonnets, listed numerically from 1 to 154 with an index to their first lines, and other miscellaneous texts. Contained also in this third volume is a list of anthologies with each of their contents cross-indexed to its entry in the main catalogue.

Volume 4 contains four indexes: Shakespeare's titles and first lines; titles of musical works; composers, arrangers, and editors; and librettists and other writers. The selected bibliography comprising Volume 5 rounds out the work. A useful reader's guide, along with abbreviations used for musical terms, library abbreviations, and, interestingly, a list of publishers' names and addresses begin volume 1 .

Under each literary title, the musical works, numbered sequentially, are ar- 
ranged in seven categories: incidental music, operas and related music, nontheatrical vocal music, nontheatrical instrumental music, settings of combined and/or unidentified texts, obliquely related works, and non-Shakespearean works. Further subarrangement is alphabetical by composer with title and other bibliographical information, instrumentation, first performance details, repositories of the music, and the author's informative annotations. An overview of musical stage directions for each play precedes its musical listings.

Unlike earlier bibliographies, the author includes works from the vast literature of incidental music, but limits this chiefly to major productions. Other new features include projected works or works left unfinished, as well as compositions misattributed to Shakespeare or easily mistaken for settings of his work.

The audience for this work is wide. Literary scholars expanding their understanding of Shakespeare's texts, musicologists studying relationships between text and music, producers and performers wanting source material for performance, cultural historians documenting changes in cultural tastes will all find useful information.

Most importantly, this work reveals the importance that music played, both in Shakespeare's conceptions of his works as well as in the popular reception accorded them over the past three hundred years. Only one play, The Comedy of Errors, does not explicitly require some form of music functional to the dramatic action. The authors indeed provide ample documentation for their assertion that "one reason that Shakespeare's genius is now recognized in all parts of the world is surely the role which the art of music has played in the dissemination of his works."-E.A.D.

\section{ART AND ARCHITECTURE}

Lerner, Loren R., and Mary F. Williamson. Art and Architecture in Canada: A Bibliography and Guide to the Literature to 1981/ Art et architecture au Canada: bibliographie et guide de la documentation jusqu'en 1981. Toronto: Univ. Toronto Pr., 1991. 2v. \$250 (ISBN 0-8020-58566). LC CE91-93656.
A bilingual "reference guide to the most significant contributions to the literature of Canadian art and architecture published in Canada and abroad from 1825 to 1981" (preface). The 9,555 bibliographic entries are annotated, many with abstracts in French and English. They are based on references located in four existing periodical indexes and specialized bibliographies and on the National Gallery of Canada catalog holdings for monographs, exhibition catalogs, some theses, journals and journal articles, and association reports. "Emphasis is on the elusive retrospective literature, the indispensable foundation for art historical research."

Volume 1, the bibliography, is organized by topic, geographical area, and chronological period, as outlined in a detailed table of contents, and is preceded by a preface that serves as a solid and thoughtful introduction to the study of Canadian art history. Volume 2, the index, provides access by author and by English and French subject entries. The overall effect is similar to that of Arts in America: A Bibliography (Guide BE11).

Two related and recent bibliographies for Canadian studies, both also bilingual, are Claude Bergeron's Index des periodiques d'architecture canadiens, 1940-1980/ Canadian Architectural Periodicals Index (Suppl. BE117) and Repertoire des dossiers documentaires traitant de l'art et de l'architecture dans les regions representées à la section ARLIS MOQ/Directory of Vertical File Collections on Art and Architecture Represented by ARLIS M/O/Q (Suppl. BE51).-K.D.C.

Thomison, Dennis. The Black Artist in America: An Index to Reproductions. Metuchen, N.Y.:Scarecrow, 1991.396 p. $\$ 47.50$ (ISBN 0-8108-2503-1). LC 91-33050.

This index was "published in order to provide easy access to the published reproduction of fine art by American Black artists ... in books, periodicals, and exhibition catalogs" (introduction) and is part of the growing genre of such publications.

The body of the work is an alphabetical listing of some one thousand artists from the colonial period to the present, giving names, dates, birthplace when available, and media, followed by citations 
for biographical sources, portraits, published reproductions, and further references, as pertinent. Citations are to a list of some 560 American publications, most from the 1960s through the 1980s. Front matter also includes names of the hundred institutions and collections consulted. A "Sources of Information" section is "designed to help the researcher do more extensive investigation" and includes monographs devoted to single artists, periodical articles, and bibliographies and then goes further to include doctoral dissertations, audiovisual materials, audiovisual producers and distributors, and exhibition catalogs. A modest subject index completes the volume.

While multiple references are made to earlier reference works-most notably Theresa Cederholm's Afro-American Artists: A Bio-Bibliographical Directory (Guide BE180)-there are no references for the field of photography. In fact, this subject is overlooked entirely in the front matter, which is surprising given the decision to include folk art and in light of the author's position as a librarian and faculty member at the University of Southern California. Thus, the two works by Deborah Willis-Thomas will be useful with the current volume: Black Photographers (Suppl. BF64n) and An Illustrated Bio-Bibliography of Black Photographers, 1940-1988 (Suppl. BF64).-K.D.C.

\section{POPULAR CULTURE}

Handbook of French Popular Culture. Ed.

Pierre L. Horn. Westport, Conn.: Greenwood , 1991. 307p. $\$ 55$ (ISBN 0-313261210). LC 90-23170.

Inspired by scholarly studies of daily life, such as Fernand Braudel's Structures $d u$ quotidien, and modeled after the Handbook of American Popular Culture (Suppl. CF34), this collection of bibliographic essays by thirteen American and French scholars explores areas of popular culture: advertising, comics, detective stories, science fiction, cartoons, film, broadcasting, culinary matters, leisure, love, music, serial publications, and sports.

Each chapter surveys historical background, analyzes trends, comments on relevant studies, and offers suggestions for further research and reading. Notes and bibliographies cite both English and French works. The volume concludes with a bibliog-raphy of general sources, a list of museums, and an index by topic and cited author.-J.S.

\section{WOMEN'S STUDIES}

Women in the West: A Guide to Manuscript Sources. Ed. Susan Armitage and others. Women's History and Cultures, 5; Garland Reference Library in the Humanities, 1086. New York: Garland, 1991. 422p. \$59 (ISBN 0-8240-4298-0). LC 91-24898.

Intended to supplement Andrea Hinding's Women's History Sources (Guide CC554), this guide includes repositories in twenty western states, from Minnesota to Hawaii. Entries are arranged geographically, list addresses and hours, and describe services, principal holdings, multicultural materials, collections of special note, and guides. There are no indexes, although a list of repositories arranged alphabetically by state completes the volume. This volume expands descriptions and includes some repositories not listed in Hinding. - S.S.

\section{AREA STUDIES}

Hartness, Ann. Brazil in Reference Books, 1965-1989: An Annotated Bibliography. Metuchen, N.J.: Scarecrow, 1991.351p. $\$ 39.50$ (ISBN 0-810-82400-0). LC 90 28356.

Haiti: Guide to the Periodical Literature in English, 1800-1990. Comp. and ed. Frantz Pratt. Bibliographies and Indexes in Latin American and Caribbean Studies, 1. Westport, Conn.: Greenwood, 1991. 310p. \$45 (ISBN 0-313-27855-5). LC 91-7572.

Latin America is a hot topic in many libraries today and librarians will welcome any guide to the literature. These two bibliographies, unfortunately, though useful, do have faults.

Brazil in Reference Books was compiled by the acting field director of the Library of Congress Office in Rio de Janeiro and is an annotated listing of reference books published in any language, though Portuguese dominates. It is divided into broad chapters (agriculture, 
ranged in seven categories: incidental music, operas and related music, nontheatrical vocal music, nontheatrical instrumental music, settings of combined and/or unidentified texts, obliquely related works, and non-Shakespearean works. Further subarrangement is alphabetical by composer with title and other bibliographical information, instrumentation, first performance details, repositories of the music, and the author's informative annotations. An overview of musical stage directions for each play precedes its musical listings.

Unlike earlier bibliographies, the author includes works from the vast literature of incidental music, but limits this chiefly to major productions. Other new features include projected works or works left unfinished, as well as compositions misattributed to Shakespeare or easily mistaken for settings of his work.

The audience for this work is wide. Literary scholars expanding their understanding of Shakespeare's texts, musicologists studying relationships between text and music, producers and performers wanting source material for performance, cultural historians documenting changes in cultural tastes will all find useful information.

Most importantly, this work reveals the importance that music played, both in Shakespeare's conceptions of his works as well as in the popular reception accorded them over the past three hundred years. Only one play, The Comedy of Errors, does not explicitly require some form of music functional to the dramatic action. The authors indeed provide ample documentation for their assertion that "one reason that Shakespeare's genius is now recognized in all parts of the world is surely the role which the art of music has played in the dissemination of his works."-E.A.D.

\section{ART AND ARCHITECTURE}

Lerner, Loren R., and Mary F. Williamson. Art and Architecture in Canada: A Bibliography and Guide to the Literature to 1981/ Art et architecture au Canada: bibliographie et guide de la documentation jusqu'en 1981. Toronto: Univ. Toronto Pr., 1991. 2v. \$250 (ISBN 0-8020-58566). LC CE91-93656.
A bilingual "reference guide to the most significant contributions to the literature of Canadian art and architecture published in Canada and abroad from 1825 to 1981" (preface). The 9,555 bibliographic entries are annotated, many with abstracts in French and English. They are based on references located in four existing periodical indexes and specialized bibliographies and on the National Gallery of Canada catalog holdings for monographs, exhibition catalogs, some theses, journals and journal articles, and association reports. "Emphasis is on the elusive retrospective literature, the indispensable foundation for art historical research."

Volume 1, the bibliography, is organized by topic, geographical area, and chronological period, as outlined in a detailed table of contents, and is preceded by a preface that serves as a solid and thoughtful introduction to the study of Canadian art history. Volume 2, the index, provides access by author and by English and French subject entries. The overall effect is similar to that of Arts in America: A Bibliography (Guide BE11).

Two related and recent bibliographies for Canadian studies, both also bilingual, are Claude Bergeron's Index des periodiques d'architecture canadiens, 1940-1980/Canadian Architectural Periodicals Index (Suppl. BE117) and Repertoire des dossiers documentaires traitant de l'art et de l'architecture dans les regions representées à la section ARLIS MOQ/Directory of Vertical File Collections on Art and Architecture Represented by ARLIS M/O/Q (Suppl. BE51).-K.D.C.

Thomison, Dennis. The Black Artist in America: An Index to Reproductions. Metuchen, N.Y.:Scarecrow, 1991.396 p. $\$ 47.50$ (ISBN 0-8108-2503-1). LC 91-33050.

This index was "published in order to provide easy access to the published reproduction of fine art by American Black artists ... in books, periodicals, and exhibition catalogs" (introduction) and is part of the growing genre of such publications.

The body of the work is an alphabetical listing of some one thousand artists from the colonial period to the present, giving names, dates, birthplace when available, and media, followed by citations 
for biographical sources, portraits, published reproductions, and further references, as pertinent. Citations are to a list of some 560 American publications, most from the 1960s through the 1980s. Front matter also includes names of the hundred institutions and collections consulted. A "Sources of Information" section is "designed to help the researcher do more extensive investigation" and includes monographs devoted to single artists, periodical articles, and bibliographies and then goes further to include doctoral dissertations, audiovisual materials, audiovisual producers and distributors, and exhibition catalogs. A modest subject index completes the volume.

While multiple references are made to earlier reference works-most notably Theresa Cederholm's Afro-American Artists: A Bio-Bibliographical Directory (Guide $B E 180$ )-there are no references for the field of photography. In fact, this subject is overlooked entirely in the front matter, which is surprising given the decision to include folk art and in light of the author's position as a librarian and faculty member at the University of Southern California. Thus, the two works by Deborah Willis-Thomas will be useful with the current volume: Black Photographers (Suppl. BF64n) and An Illustrated Bio-Bibliography of Black Photographers, 1940-1988 (Suppl. BF64).-K.D.C.

\section{POPULAR CULTURE}

Handbook of French Popular Culture. Ed. Pierre L. Horn. Westport, Conn.: Greenwood , 1991. 307p. \$55 (ISBN 0-313261210). LC 90-23170.

Inspired by scholarly studies of daily life, such as Fernand Braudel's Structures du quotidien, and modeled after the Handbook of American Popular Culture (Suppl. CF34), this collection of bibliographic essays by thirteen American and French scholars explores areas of popular culture: advertising, comics, detective stories, science fiction, cartoons, film, broadcasting, culinary matters, leisure, love, music, serial publications, and sports.

Each chapter surveys historical background, analyzes trends, comments on relevant studies, and offers suggestions for further research and reading. Notes and bibliographies cite both English and French works. The volume concludes with a bibliog-raphy of general sources, a list of museums, and an index by topic and cited author.-J.S.

\section{WOMEN'S STUDIES}

Women in the West: A Guide to Manuscript Sources. Ed. Susan Armitage and others. Women's History and Cultures, 5; Garland Reference Library in the Humanities, 1086. New York: Garland, 1991. 422p. \$59 (ISBN 0-8240-4298-0). LC 91-24898.

Intended to supplement Andrea Hinding's Women's History Sources (Guide CC554), this guide includes repositories in twenty western states, from Minnesota to Hawaii. Entries are arranged geographically, list addresses and hours, and describe services, principal holdings, multicultural materials, collections of special note, and guides. There are no indexes, although a list of repositories arranged alphabetically by state completes the volume. This volume expands descriptions and includes some repositories not listed in Hinding.-S.S.

\section{AREA STUDIES}

Hartness, Ann. Brazil in Reference Books, 1965-1989: An Annotated Bibliography. Metuchen, N.J.: Scarecrow, 1991.351p. $\$ 39.50$ (ISBN 0-810-82400-0). LC 9028356.

Haiti: Guide to the Periodical Literature in English, 1800-1990. Comp. and ed. Frantz Pratt. Bibliographies and Indexes in Latin American and Caribbean Studies, 1. Westport, Conn.: Greenwood, 1991. 310p. \$45 (ISBN 0-313-27855-5). LC 91-7572.

Latin America is a hot topic in many libraries today and librarians will welcome any guide to the literature. These two bibliographies, unfortunately, though useful, do have faults.

Brazil in Reference Books was compiled by the acting field director of the Library of Congress Office in Rio de Janeiro and is an annotated listing of reference books published in any language, though Portuguese dominates. It is divided into broad chapters (agriculture, 
architecture, etc.), which are further subdivided into types (bibliographies, dictionaries) or subtopics. This is a useful arrangement, though a classified table of contents would help immeasurably in locating the subtopics. And the arrangement is sometimes too general to be of much use. The chapter on bibliographies, for instance, lists in one alphabetical sequence publications ranging from the various national bibliographies to a bibliography of agrarian reform. The very useful book on Brazil in the Area Handbook Series is listed under "General sources-other sources," not under "Politics and government," and seems to be impossible to locate through the subject index. The book described in the annotation as providing "explanations and instructions for practicing the rituals of candomble written for the novice" (p. 274) seems to be stretching the definition of a reference book.The beginning date of 1965 also means that this guide, while it contains many useful references, can never be as useful as a retrospective bibliography.

Any librarian who has used the useful but cumbersome Complete Haitiana (Guide DB439) will be thrilled by the thought of Haiti: Guide to Periodical Literature in English. But opening the book is like déjà vu all over again, understandable when one learns that the compiler is associated with Lambros Comitas's Institute for the Study of Man.

It is arranged by nine broad topics (the physical setting, the human element, philately, etc.), then by subdivisions which are explained in the "Notes to the User." Entries are arranged chronologically under each subdivision. Once the shock of the typefaces wears off (the entries are completely capitalized, with the article titles italicized and the journals in boldface) the reader can find a great deal of useful information, though this must be used with care. Surely the Nation and the National Catholic Reporter did not both publish C. McGill's article "Haitians in Limbo" on the same date and page.

There are author and journal title indexes, but no subject index. The indexes again use all capital letters, strung across the pages with no punctuation separating the different references; they are essentially useless. It is disappointing that the publisher allowed such a useful title to be so poorly presented.-M.C.

\section{HEALTH SCIENCES}

Vision and Visual Dysfunction. Ed. John R. Cronly-Dillon. Boca Raton, Fla: CRC Pr., 1991. 17v. (each paginated separately). $\$ 1,995 /$ set, $\$ 215 /$ volume (ISBN 0-8493-7500-2). LC 90-1881.

This seventeen-volume encyclopedia, originally published in England by the Macmillan Press (1990-91), is constructed around sixteen subject areas. Each comprises a volume on a topic such as visual optics and instrumentation, perception of color, spatial vision, dyslexia, and pattern recognition. The general editor, John Cronly-Dillon, is professor and chairman of the Department of Optometry and Vision Sciences at the University of Manchester Institute of Science and Technology in England. His purpose is to reflect the multidisciplinary trend in vision science and to provide a repository of current knowledge in the main areas of the field.

Each volume is edited by one or more subject specialists and stands as a coherent work in its own right. The contributors are from the United States, the United Kingdom, Europe, Canada, and Australia. All chapters have been refereed, and the aim throughout has been not only to review current material, but also to explore new ideas and issues that may stimulate novel directions in research. Each volume has its own index, and Volume 17 is a complete contents list and index to all the volumes.

Vision and Visual Dysfunction will be kept up to date by the publication of supplementary volumes that will contain brief summaries of important experimental research results and their developments. It is a unique encyclopedia of by far the greatest breadth and depth of any work ever published on the subject of vision. Scientists, clinicians, and engineers have an extraordinary new reference work on the many facets of a topic that has been the subject of intense activity 
over the last forty years. Fortunately this resource can be purchased as a whole or in individual volumes.- - L.H.

\section{NEW EDITIONS AND SUPPLEMENTS}

Ralph DeSola has expanded the Abbreviations Dictionary (6th ed., 1981. Guide AD36). Now in an eighth edition (Boca Raton, Fla.: CRC Pr., 1992. 1,300p. \$69.95; 7th ed., 1986), the volume offers such features as special lists of zip-coded automatic-processing abbreviations, bell-code signals, criminal and military terms (also featured in DeSola's Worldwide What \& Where and his (rime Dictionary), frequently used signs and symbols such as abbreviations of the airline industry and of naval craft. An appendix includes a list of musical superlatives and of eponyms. The volume is not indexed.

The American Men \& Women of Science, 1992-1993: Physical and Biological Sciences is the eighteenth edition (N.Y.: Bowker, [1992]. 8v. \$750; 17th ed., 1989. Suppl. EA75) and has grown to 122,817 engineers and scientists including 7,021 entirely new entries. A small statistical section begins Volume 1.

The Index to Volumes 1-12 of the Australian Dictionary of Biography, 17881939 (Melbourne: Univ. Pr; London: Cambridge Univ. Pr., [1991]. 326p. See Guide AJ115, Suppl. AJ33 for the set) "references the names of 10,442 individuals, including the 7,211 major entries in the A.D.B. as well as every minor (small-capped) entry and many lesser ones. It also divides these people into 379 separate occupational categories. It further sets out the 612 different countries in which they were born, subdividing these places into states or counties, cities or towns, villages or pastoral stations" (Preface). A consolidated list of corrigenda is included.

In 1977 J. Gordon Melton compiled Religious Bodies in the United States: A Directory based on files at the Institute for Study of American Religion in Santa Barbara, California. He has gone back to these files and has compiled a listing for each religious group known to be operating in the United States as of the summer of 1991, along with its headquarters address and telephone number and a brief paragraph of identification (New York: Garland, 1992. 312 p. \$55 Adding to its usefulness is an alphabetical index which includes alternate names.

Invest Yourself: The Catalogue of Volunteer Opportunities. Ed. Susan G. Angus (New York: Commission on Voluntary Service and Action, 1991. 128p. \$7.95) has grown to include about two hundred nongovernmental organizations which offer voluntary service opportunities. Alphabetically organized, the volume provides geographical and category indexes.

Index Islamicus (Guide. BB518) has a sixth supplement covering 34,382 entries from the Quarterly Index Islamicus for 19811985 (ed. G. J. Roper. London: Mansell, [1991]. 2v. (1,347p.) £130). This cumulation takes into account the new sections on music and drama, economics, politics, and Muslim minorities which appeared with the 1983 issues, as well as elaborated subheadings. A subject index is also new. The editor points out that the output of scholarship on the Muslim world is doubling every ten years.

The Reference Library of Black America (Philadelphia: Afro-American Pr., [1990]. $5 \mathrm{v} . \$ 179.90)$ is a repackaging of the fifth edition of the Negro Almanac (Detroit: Gale, 1989) "to facilitate usage among students" (title page).

Gale has been reprinting excerpts from critical writings about various authors and their works, e.g., Contemporary Literary Criticism (Guide BD43), Twentieth-Century Literary Criticism (Guide BD47), Short Story Criticism (Suppl. BD99). There are two new collections which are partly drawn from the earlier volumes in the Literary Criticism Series: Poetry Criticism (v.1, 1991) whose compiler states that this title does not duplicate CLC more than 15 percent and Black Literature Criticism (1992. 3v). with about half the entries selected from earlier volumes, but revised.

Richard A. Lanham has reviewed his Handlist of Rhetorical Terms (Berkeley: Univ. Calif. Pr., [1991]. 205p. \$35; 1st ed. 1968. Guide BD347) to provide for easier use, to supply more and more modern examples, and to revise and update the bib- 
liography. It is still very much a beginner's guide.

The second edition of the Oxford Companion to American Theatre by Gerald Bordman is still as opinionated, entertaining, and useful as the first (New York: Oxford Univ. Pr., 1992. 734p. $\$ 49.95$; 1 st ed., Guide BG56). Added are "significant figures, groups, and plays which have appeared since our first writing and the end of 1990" (preface). There are one-sentence updates to many of the articles, and there is still no index.

Christoph Kimmich has updated his German Foreign Policy, 1918-1945: A Guide to Research and Research Materials (Wilmington, Del.: Scholarly Resources, [1991]. 264p. \$40; 1st ed., 1981, Guide DC197). Entries for the archives and libraries have been updated, but it is in the bibliographic portions that the most new material has been added both in the footnotes and in the bibliography chapters. Similar updating has occurred with the French, Italian, German, British, and International Organizations volumes, and new guides for the Soviet Union and for International Economic Relations have appeared.

Research Guide to Libraries and Archives in the Low Countries, comp. Martha L. Brogan (Westport, Conn.: Greenwood, [1991]. 546p. \$75) is similar in arrangement and information to the others in the series commissioned by the Council of European Studies (see the two volumes by E. K. Welsch on France and Germany, Guide $\mathrm{AB} 133, \mathrm{AB} 136$, and by Lewanski for Italy, Guide AB148). This volume covers libraries and archives in Belgium, the Netherlands, and Luxembourg and gives references to any user's guides or books and articles for further reading as well as the expected information on size, address, classification, services, and description, but not hours as the other volumes have done. Additional bibliographical sections feature lists of national bibliographies, union catalogs, national biographical dictionaries, directories and guides to collections, subject guides, and bibliographies. The volume is well indexed. 


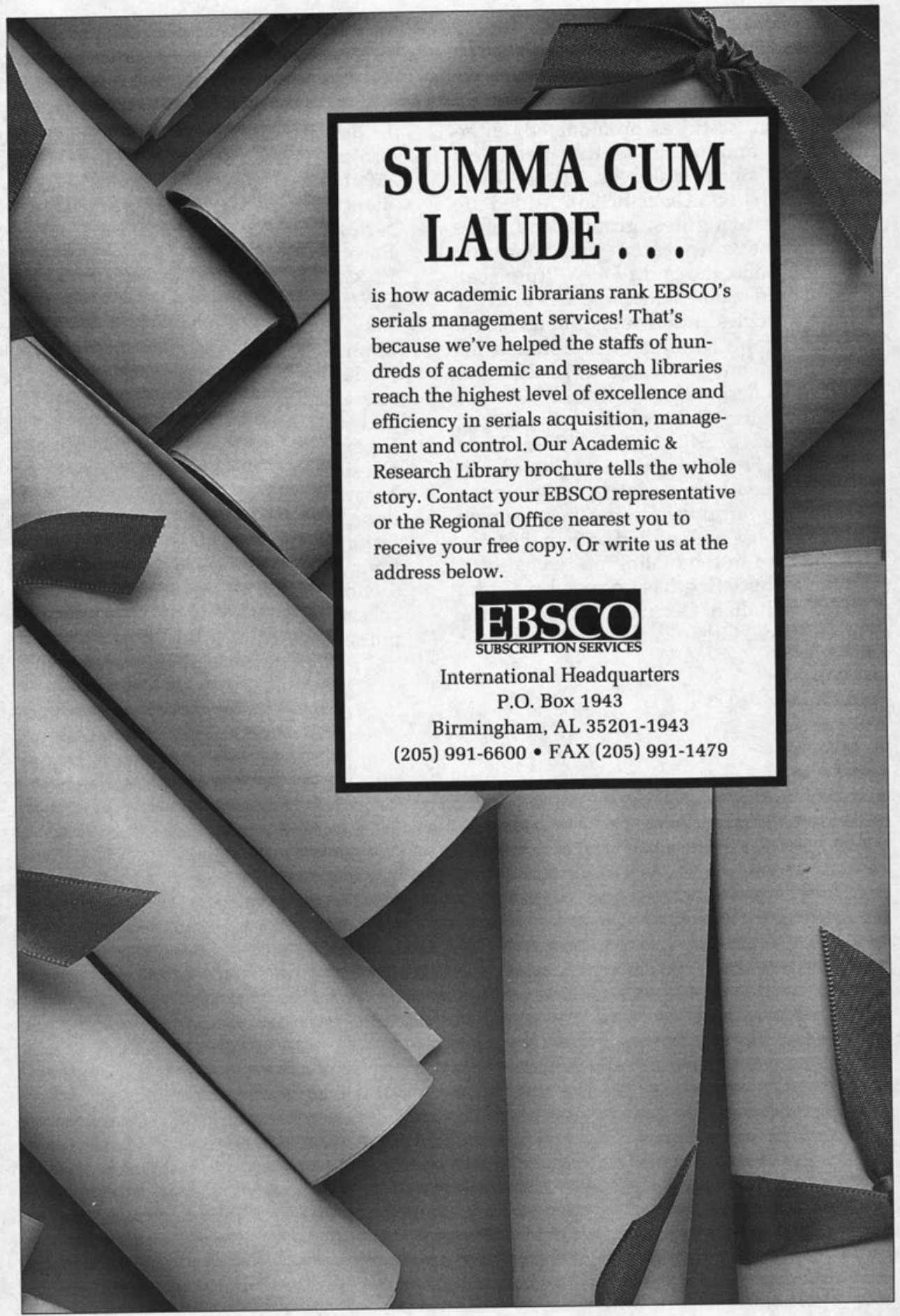

